\title{
Increasing airway obstruction from 8 to 18 years in extremely preterm/low-birthweight survivors born in the surfactant era
}

\author{
Lex W Doyle, ${ }^{1,2,3,4}$ Anne-Marie Adams, ${ }^{5}$ Colin Robertson, ${ }^{5}$ Sarath Ranganathan, ${ }^{5}$ \\ Noni M Davis, ${ }^{1}$ Katherine J Lee, ${ }^{6}$ Jeanie L Cheong, ${ }^{1,2,3}$ on behalf of the Victorian \\ Infant Collaborative Study Group
}

\begin{abstract}
- Additional material is published online only. To view please visit the journal online (http://dx.doi.org/10.1136/ thoraxjnl-2016-208524)
\end{abstract}

For numbered affiliations see end of article.

Correspondence to Professor LexW Doyle, Research Office, Royal Women's Hospital, 20 Flemington Rd, Parkville, VIC 3052, Australia;

Iwd@unimelb.edu.au

Received 22 February 2016 Revised 27 July 2016 Accepted 2 August 2016 Published Online First 5 September 2016

\section{Linked}

http://dx.doi.org/10.1136/ thoraxjnl-2016-208985

- http://dx.doi.org/10.1136/ thoraxjnl-2016-209291

CrossMark

To cite: Doyle LW,

Adams A-M, Robertson C,

et al. Thorax

2017;72:712-719.

\section{ABSTRACT}

Background The evolution of airway obstruction into late adolescence of extremely preterm (gestational age $<28$ weeks) or extremely low-birthweight (birth weight $<1000 \mathrm{~g}$ ) survivors in the era after surfactant was introduced is unclear.

Objective To compare changes in spirometry from 8 to 18 years of age of a geographical cohort of preterm survivors with normal birth weight controls, and to determine higher risk groups within the preterm cohort. Methods Of 297 extremely preterm/low-birthweight survivors born in 1991-1992 in the state of Victoria, Australia, $81 \%$ and $70 \%$ had spirometry at 8 and 18 years of age, respectively. Corresponding rates among 260 normal birth weight controls were $80 \%$ and $58 \%$, respectively. Data were analysed using linear mixed models.

Results The preterm group had substantial impairments in airflow at both ages compared with controls (eg, mean differences in z-score for $\mathrm{FEV}_{1}$; 8 years $-1.02,95 \% \mathrm{Cl}-1.21$ to $-0.82 ; 18$ years $-0.92,95 \% \mathrm{Cl}-1.14$ to -0.71$)$. The preterm group had a greater increase in small airway obstruction between 8 and 18 years compared with controls. Within the preterm group, those who had bronchopulmonary dysplasia in the newborn period and those who were smokers at 18 years had airway obstruction that increased over time compared with those who did not. Conclusions Preterm survivors born in the surfactant era had significant impairments in airflow through childhood into late adolescence that increased over time compared with controls. At-risk preterm participants include those who had bronchopulmonary dysplasia, and smokers at 18 years.

\section{INTRODUCTION}

Lung growth occurs throughout fetal life and childhood, normally peaking in the mid-20s, after which there is a gradual decline in lung function with age. ${ }^{1}$ As other causes of death intervene, most people never develop symptomatic lung disease from the natural decline in lung function as they age. Those who smoke, however, have an accelerated decline in lung function, ${ }^{2}$ can become symptomatic and some die from COPD.

To survive, most extremely preterm (EP; birth $<28$ weeks' gestational age) infants require assisted

\section{Key messages}

What is the key question?

- What is the trajectory of airway obstruction in survivors of extreme prematurity from childhood to late adolescence, particularly in the era when exogenous surfactant was available for clinical use?

What is the bottom line?

- This study reports for the first time that airway obstruction increased between 8 and 18 years in extremely preterm/low-birthweight survivors born in the era when surfactant was used clinically, particularly in those who had bronchopulmonary dysplasia in the newborn period, and those who were smoking at 18 years.

\section{Why read on?}

- Extremely preterm/low-birthweight survivors born in the surfactant era are highly unlikely to achieve the full airway growth into adulthood and seem destined for earlier onset adult chronic obstructive airway disease.

ventilation, which has evolved since the 1970 s when it was first widely used. However, immature lungs are not meant to be exposed to air, much less to higher concentrations of oxygen or to mechanical ventilation, all of which can damage the lungs, sometimes leading to bronchopulmonary dysplasia (BPD). BPD was first described in $1967^{3}$ when few preterm infants received mechanical ventilation and when survival rates of preterm infants were very low. The description of BPD was updated in $2001^{4}$ and is more relevant to preterm infants surviving today. As survival rates of EP/extremely lowbirthweight (ELBW; birth weight $<1000 \mathrm{~g}$ ) infants have risen dramatically since the $1970 \mathrm{~s}^{5}{ }^{6}$ with the evolution of perinatal and neonatal care, including the introduction of exogenous surfactant from the 1990s, more infants are reaching adulthood, and there is an urgent need to determine their longterm pattern of lung function, particularly airway function. 
The trajectory of airway function of EP/ELBW survivors has not commonly been described into adulthood, largely because few such infants have survived to adulthood and had repeated measurements of pulmonary function. Most, ${ }^{7-15}$ but not all, ${ }^{16}$ studies that have reported spirometry data in late adolescence or early adulthood have reported substantial reductions in airflow for preterm survivors compared with controls. Within the preterm cohorts, those who had BPD in the newborn period had even more reductions in airflow than did those without BPD. However, all but one ${ }^{12}$ of these studies reported outcomes from the era before surfactant was available. Moreover, only a few of these studies ${ }^{11} 1416$ have reported on changes in spirometry from childhood through to late adolescence or early adulthood. Only one study from Norway, comprising 35 preterm survivors, was from the surfactant era, and it reported little evidence of differential airway obstruction from 10 and 17 years between preterm and control participants. ${ }^{11}$ Another important variable is cigarette smoke exposure, which can also affect airway function in childhood, ${ }^{17}$ but was not investigated in the Norwegian study as only one of the 35 preterm participants was a smoker. ${ }^{11}$

The aims of this study of EP/ELBW survivors were (1) to compare airflow at 8 and 18 years and changes between 8 and 18 years of EP/ELBW survivors with normal birth weight controls, and (2) within the EP/ELBW group, to determine the associations of BPD in the newborn period, and of active smoking in adolescence with airflow. We hypothesised that EP/ELBW survivors would have substantially reduced airflow at both ages, and a reduced trajectory of airflow between 8 and 18 years compared with controls. Within the EP/ELBW group, we hypothesised that those who had BPD and those who were active smokers at 18 years would have a greater decline in airflow between 8 and 18 years than participants without these exposures.

\section{METHODS}

\section{Study groups}

The preterm cohort for this study comprised all survivors born either EP or ELBW in 1991 and 1992 in the state of Victoria, Australia. Survival rates to 18 years of age were $56 \%(224 / 401)$ for infants 23-27 weeks' gestational age and 56\% (240/429) for those with 500-999 g birth weight, resulting in 297 survivors overall. Normal birth weight $(>2499 \mathrm{~g})$ controls $(n=260)$ were randomly selected from births on the date that a preterm survivor was due to be born, matched for sex of the infant, the mother's health insurance status (private or not, as a proxy for social class) and the mother's country of birth (primarily English-speaking or not). The cohorts have been previously assessed at $2,^{18}{ }^{19} 5^{20}$ and $8^{21}$ years, including spirometry at $8^{22}$ years. They were reassessed in late adolescence, at a mean age of 18 years (range $16-20$ years).

\section{Perinatal and respiratory data}

Perinatal data collected in the newborn period included variables shown in table 1. Exogenous surfactant (Exosurf) was introduced clinically in Victoria in 1991, but was initially limited to those requiring assisted ventilation via an endotracheal tube and more than 50\% oxygen. After 1991, surfactant could be given more liberally. BPD was defined as oxygen or ventilator dependency at 36 weeks' postmenstrual age, consistent with moderate or severe BPD according to the subsequent National Heart, Lung and Blood Institute-sponsored workshop definition. ${ }^{4}$
Table 1 Characteristics of the preterm and control groups

\begin{tabular}{|c|c|c|}
\hline Variable & $\begin{array}{l}\text { Preterm } \\
\mathrm{n}=297\end{array}$ & $\begin{array}{l}\text { Control } \\
n=260\end{array}$ \\
\hline Antenatal corticosteroids & $216(73 \%)$ & $3(1 \%)$ \\
\hline Caesarean delivery & $113(38 \%)$ & $31(12 \%)$ \\
\hline Gestational age (completed weeks)—mean (SD) & $26.7(1.9)$ & $39.2(1.4)$ \\
\hline Birth weight $(\mathrm{g})$-mean (SD) & $888(161)$ & $3386(438)$ \\
\hline Male & $137(46 \%)$ & $126(48 \%)$ \\
\hline Birth weight z-score & $-0.73(1.19)$ & $-0.02(0.88)$ \\
\hline Exogenous surfactant & $119(40 \%)$ & $0(0 \%)$ \\
\hline Assisted ventilation & $281(95 \%)$ & $0(0 \%)$ \\
\hline Bronchopulmonary dysplasia* & $121(41 \%)$ & $0(0 \%)$ \\
\hline Postnatal corticosteroids & $97(33 \%)$ & $0(0 \%)$ \\
\hline Assessed at 8 years of aget & $273(92 \%)$ & $221(85 \%)$ \\
\hline Spirometry at 8 years & $240(81 \%)$ & $208(80 \%)$ \\
\hline Age of spirometry at 8 years-mean (SD) & $8.7(0.3)$ & $8.9(0.4)$ \\
\hline Assessed at 18 years of age $\ddagger$ & $220(74 \%)$ & $166(64 \%)$ \\
\hline Spirometry at 18 years & $209(70 \%)$ & $154(58 \%)$ \\
\hline Age of spirometry at 18 years-mean (SD) & $17.9(0.8)$ & $18.0(0.8)$ \\
\hline Smoking at 18 years§ & $35 / 205(17 \%)$ & $21 / 152(13 \%)$ \\
\hline Asthma at 18 years§ & 40/189 (21\%) & $27 / 143(19 \%)$ \\
\hline
\end{tabular}

Data are $\mathrm{n}(\%)$, unless otherwise specified.

*Defined as oxygen or ventilator dependency at 36 weeks.

tOf the 24 participants in the EP/ELBW group not assessed at 8 years, 8 were lost to follow-up, 4 were inaccessible, 11 refused and 1 had only a partial assessment. Of the 39 participants in the control group not assessed at 8 years, 22 were lost to follow-up, 4 were inaccessible and 13 refused.

$\ddagger$ of the 77 participants in the EP/ELBW group not assessed at 18 years, 15 were lost to follow-up, 3 were inaccessible, 40 refused (including 8 with major disability at 8 years) and 19 had miscellaneous reasons (including 11 with major disability at 8 years). Of the 94 participants in the control group not assessed at 18 years, 30 were lost to follow-up, 5 were inaccessible, 54 refused (including 2 with major disability at 8 years) and 5 had miscellaneous reasons (including 2 with major disability at 8 years)

$\S 0$ those with spirometry data at 18 years.

ELBW, extremely low birth weight; EP, extremely preterm.

At 18 years, participants were asked about current smoking and asthma status.

\section{Spirometry}

Spirometry was assessed at the follow-ups at 8 and 18 years by respiratory scientists who were unaware of the perinatal details of the cohorts or of group status. Regular bronchodilators were withheld on the morning of testing. Lung function was measured on the Jaeger body plethysmography (Jaeger MasterScreen body, Würzburg, Germany) using Lab Manager V.4.67a software, calibrated daily for volume using a $3 \mathrm{~L}$ syringe (Viasys Healthcare, Würzburg, Germany, serial number 95318048, calibration valid July 2009). Lung function was measured according to the American Thoracic Society and European Respiratory Society guidelines. ${ }^{23}$

Forced expiratory flow was measured using spirometry at baseline and post bronchodilator response (BDR; $400 \mathrm{mcg}$ salbutamol via metered dose inhaler and volumetric spacer device). Post BDRs were not routine at the 8-year assessment, and were only assessed in participants with $\mathrm{FEV}_{1}<80 \%$ predicted. Other variables measured included FVC, the ratio of $\mathrm{FEV}_{1} / \mathrm{FVC}$, forced expiratory flow at 25\%-75\% of FVC $\left(\mathrm{FEF}_{25 \%-75 \%}\right)$ and forced expiratory flow at $75 \%$ of $\mathrm{FVC}$ expired $\left(\mathrm{FEF}_{75 \%}\right)$. Results were converted to $\mathrm{z}$-scores $\left(\mathrm{zFEV}_{1}\right.$, zFVC, $\mathrm{zFEV}_{1} / \mathrm{FVC}, \mathrm{zFEF}_{25 \%-75 \%}$, and $\mathrm{zFEF}_{75 \%}$ ) and per cent predicted for age, height, sex and ethnicity, as per the Global Lung Initiative 2012 reference values. ${ }^{24} \mathrm{~A}$ change in $\mathrm{FEV}_{1}$ of at least $12 \%$ was considered to represent a clinically important BDR to salbutamol. 


\section{Ethics}

The initial and follow-up studies were approved by the human research ethics committees at the Royal Women's Hospital, the Mercy Hospital for Women, Monash Medical Centre and the Royal Children's Hospital, Melbourne. Participants gave written informed consent, as did their parents if the participants were under 18 years of age.

\section{Statistical analysis}

Data were analysed using Stata V.14.1. For BDRs, continuous data were compared between groups using t test, with ORs from logistic regression models and 95\% CIs calculated for comparisons of proportions. Changes over time in the prebronchodilator variables were compared between the EP/ELBW and control groups (Aim 1) using linear mixed models, which enable participants to be included if they were assessed at either 8 or 18 years of age. Group and time are modelled as fixed effects, as well as an interaction between group and time, to determine if there were differences in rates of change over time between the two groups. Random effects were used to allow for the repeated measures within individuals. Within the preterm cohort alone (Aim 2), changes in spirometry from 8 to 18 years of age were compared between those who had BPD and those who did not in the newborn period, and between those who were smokers and those who were not smokers at 18 years, using linear mixed models, including each of these variables in separate regression models, along with interactions between the variables and time. Again, random effects allowed for repeated measures within individuals. The latter analysis was restricted to those with smoking data at 18 years.

The items for matching when the participants were infants were designed to ensure balance for variables known primarily to affect cognitive outcome, particularly in early childhood. Limiting analyses to matched pairs means that if one of a pair has missing data, the other of the pair cannot contribute to the analysis; consequently, we have not analysed data within matched pairs as we would only be reporting results on $<50 \%$ of the cohort.

The sample size for the study was determined by the calendar years of birth (1991 and 1992) and originally powered to find differences in mortality compared with preterm cohorts born in the state of Victoria in earlier eras. ${ }^{18}$ With regards to the current study, $209 \mathrm{EP} / \mathrm{ELBW}$ and 154 control participants with lung function data at 18 years enable us to detect differences in means between groups as small as $0.3 \mathrm{SD}$, with $80 \%$ power at a type-I error rate of $5 \%$ (based on a two-sided test).

\section{RESULTS}

As expected, the preterm groups were very immature and small at birth, the majority $(73 \%)$ had received antenatal corticosteroids, most were ventilated and $40 \%$ received exogenous surfactant (table 1). The cohorts were otherwise balanced for sex of the participants, and active smoking status and rates of asthma at 18 years, although there were some missing data for the latter two variables in both groups. The rates of obtaining valid spirometry data were high for both groups at 8 years, but lower at 18 years. Of note, not all participants could complete all respiratory function tests, because of poor cooperation, or unavailability or malfunctioning of equipment on the day of testing. Compared with those with spirometry data at 18 years, those without spirometry data were similar on most characteristics in both preterm and control groups, with the exceptions of lower rates of BPD in those with data in the preterm group, fewer males in those with data in the control group and lower rates of major neurosensory disability at 8 years in those with data in both groups (see online supplementary table S1). The ages when spirometry data were obtained were similar in both groups.

\section{Preterm versus control groups}

The spirometry values for the control group were close to expected values at both 8 and 18 years of age (table 2). The

Table 2 Spirometry variables at 8 and 18 years comparing preterm and control groups

\begin{tabular}{|c|c|c|c|c|c|c|}
\hline \multirow[b]{2}{*}{ Variable } & \multicolumn{2}{|l|}{8 years } & \multirow[b]{2}{*}{ Mean difference $(95 \% \mathrm{Cl})$} & \multicolumn{2}{|l|}{18 years } & \multirow[b]{2}{*}{ Mean difference $(95 \% \mathrm{Cl})$} \\
\hline & $\begin{array}{l}\text { Preterm } \\
n=240\end{array}$ & $\begin{array}{l}\text { Control } \\
n=208\end{array}$ & & $\begin{array}{l}\text { Preterm } \\
n=209\end{array}$ & $\begin{array}{l}\text { Control } \\
n=154\end{array}$ & \\
\hline \multicolumn{7}{|l|}{$\mathrm{FEV}_{1}$} \\
\hline z-score & $-0.93(1.07)$ & $0.08(1.01)$ & $-1.02(-1.21$ to -0.82$) p<0.001$ & $-1.03(1.08)^{*}$ & $-0.10(1.03)^{*}$ & $-0.92(-1.14$ to -0.71$) p<0.001$ \\
\hline$\%$ predicted & $88.8(12.8)$ & $100.9(11.8)$ & $-12.0(-14.3$ to -9.7$) p<0.001$ & $87.9(12.9)^{*}$ & $98.7(10.7)^{*}$ & $-10.9(-13.4$ to -8.4$) p<0.001$ \\
\hline \multicolumn{7}{|l|}{ FVC } \\
\hline z-score & $-0.88(1.20)$ & $-0.21(1.06)$ & $-0.67(-0.88$ to -0.46$) p<0.001$ & $-0.48(1.03)$ & $-0.09(0.87)$ & $-0.38(-0.58$ to -0.18$) p<0.001$ \\
\hline$\%$ predicted & $89.6(14.1)$ & $97.5(12.6)$ & $-7.9(-10.4$ to -9.4$) p<0.001$ & $94.4(12.1)$ & $99.0(10.4)$ & $-4.5(-6.9$ to -2.1$) p<0.001$ \\
\hline \multicolumn{7}{|l|}{$\mathrm{FEV}_{1} / \mathrm{FVC}$} \\
\hline z-score & $0.10(1.51)$ & $0.64(1.20)$ & $-0.55(-0.80$ to -0.29$) p<0.001$ & $-0.85(1.25)^{*}$ & $-0.06(0.97)^{*}$ & $-0.80(-1.03$ to -0.56$) p<0.001$ \\
\hline$\%$ & $88.4(9.2)$ & $91.4(6.6)$ & $-3.0(-4.5$ to -1.5$) p<0.001$ & $81.5(9.5)^{*}$ & $87.0(6.3)^{*}$ & $-5.5(-7.2$ to -3.7$) p<0.001$ \\
\hline \multicolumn{7}{|l|}{$\mathrm{FEF}_{25 \%-75 \%}$} \\
\hline z-score & $-1.35(1.10) \dagger$ & $-0.38(1.10)^{*}$ & $-0.96(-1.16$ to -0.77$) p<0.001$ & $-1.37(1.19)$ & $-0.23(0.98)$ & $-1.14(-1.37$ to -0.90$) p<0.001$ \\
\hline$\%$ predicted & $71.4(23.3) \dagger$ & $92.1(21.6)^{*}$ & $-20.7(-24.9$ to -16.4$) p<0.001$ & $73.1(22.9)$ & $95.9(21.4)$ & $-22.7(-27.4$ to -18.1$) p<0.001$ \\
\hline \multicolumn{7}{|l|}{$\mathrm{FEF}_{75 \%}$} \\
\hline z-score & $-0.61(1.16) \ddagger$ & $0.09(1.02) \S$ & $-0.70(-0.91$ to -0.49$) p<0.001$ & $-0.95(1.14)^{*}$ & $0.05(0.87)^{*}$ & $-1.00(-1.21$ to -0.78$) p<0.001$ \\
\hline$\%$ predicted & $85.5(35.8) \ddagger$ & $106.7(34.2) \S$ & $-21.2(-28.0$ to -14.5$) p<0.001$ & $76.4(30.8)^{*}$ & $104.7(29.7)^{*}$ & $-28.3(-34.6$ to -21.9$) p<0.001$ \\
\hline
\end{tabular}


Table 3 Changes over time for spirometric z-scores from linear mixed models, contrasting preterm and control groups

\begin{tabular}{|c|c|c|c|}
\hline \multirow[b]{2}{*}{ Variable } & \multicolumn{2}{|l|}{ Change between 8 and 18 years } & \multirow[b]{2}{*}{ Interaction } \\
\hline & Preterm & Controls & \\
\hline $\mathrm{zFEV}_{1}$ & $-0.11(-0.22$ to -0.02$) p=0.054$ & $-0.15(-0.28$ to -0.02$) p=0.022$ & $0.04(-0.13$ to 0.21$) p=0.66$ \\
\hline zFVC & 0.39 (0.27 to 0.52$) p<0.001$ & $0.13(-0.01$ to 0.27$) \mathrm{p}=0.06$ & $0.26(0.07$ to 0.45$) p=0.006$ \\
\hline $\mathrm{zFEV}_{1} / \mathrm{FVC}$ & $-0.94(-1.12$ to -0.72$) p<0.001$ & $-0.67(-0.87$ to -0.47$) p<0.001$ & $-0.27(-0.54$ to -0.01$) p=0.042$ \\
\hline $\mathrm{zFEF}_{25 \%-75 \%}$ & $-0.06(-0.20$ to 0.07$) p=0.39$ & $0.18(0.04$ to 0.31$) p=0.014$ & $-0.23(-0.42$ to -0.04$) p=0.016$ \\
\hline $\mathrm{zFEF}_{75 \%}$ & $-0.33(-0.47$ to -0.19$) p<0.001$ & $0.02(-0.14$ to 0.17$) p=0.84$ & $-0.35(-0.56$ to -0.13$) p=0.002$ \\
\hline
\end{tabular}

Values are mean difference $(95 \% \mathrm{Cl})$, unless otherwise stated.

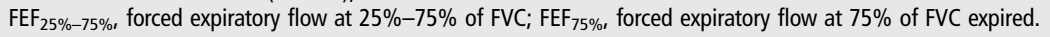

preterm group had substantially lower spirometry values at both ages compared with controls, whether the results were expressed as z-scores or as \% predicted (table 2). All spirometry variables deteriorated between 8 and 18 years in the preterm group except the zFVC, which increased over time, whereas only the $\mathrm{zFEV}_{1}$ and $\mathrm{zFEV}_{1} / \mathrm{FVC}$ deteriorated over time in the control group (table 3 ). Compared with the controls, there was strong evidence that the preterm group deteriorated between 8 and 18 years compared with controls for $\mathrm{zFEV}_{1} / \mathrm{FVC}, \mathrm{zFEF}_{25 \%-}$ $75 \%$ and $\mathrm{zFEF}_{25 \%}$, but improved for the $\mathrm{zFVC}$, as indicated by the significant interactions between group and time for those variables.

Adding cigarette smoking as a covariate altered no conclusions regarding differences between preterm and control groups.

\section{BPD versus no BPD (preterm group only)}

Within the preterm group, those who had BPD in the newborn period had substantially lower values for all spirometry values at both ages, except for $\mathrm{FEV}_{1} / \mathrm{FVC}$ at 8 years, compared with those without BPD (table 4).
All spirometry variables deteriorated between 8 and 18 years in the BPD group except the zFVC, which increased over time, whereas only the $\mathrm{zFEV}_{1} / \mathrm{FVC}$ and $\mathrm{zFEF}_{75 \%}$ deteriorated over time in the no BPD group (table 5). Compared with the no BPD group, there was strong evidence that the BPD group deteriorated between 8 and 18 years for all spirometry variables except the zFVC.

\section{Smokers versus non-smokers at 18 years (preterm group only)}

Smokers in both groups on average had been smoking for 3 years prior to the 18 -year assessment. There were no substantial differences between smokers and non-smokers for spirometry variables at both 8 and 18 years, although there were trends for smokers at 18 years for reductions in $\mathrm{zFEF}_{25 \%-75 \%}$ and $\mathrm{zFEF}_{75 \%}$ compared with non-smokers (table 6).

$\mathrm{zFEV}_{1}, \mathrm{zFEV}_{1} / \mathrm{FVC}$ and $\mathrm{zFEF}_{75 \%}$ deteriorated between 8 and 18 years in the smokers, but the zFVC increased over time, whereas only the $\mathrm{zFEV}_{1} / \mathrm{FVC}$ and $\mathrm{zFEF}_{75 \%}$ deteriorated over time and the $z F V C$ increased over time in the non-smokers (table 7). Compared with the non-smokers, there was strong

Table 4 Spirometry variables at 8 and 18 years within the preterm group comparing those with and without BPD in the newborn period

\begin{tabular}{|c|c|c|c|c|c|c|}
\hline \multirow[b]{2}{*}{ Variable } & \multicolumn{2}{|l|}{8 years } & \multirow[b]{2}{*}{$\begin{array}{l}\text { Mean difference }(95 \% \mathrm{Cl}) \text {, } \\
\text { p value }\end{array}$} & \multicolumn{2}{|l|}{18 years } & \multirow[b]{2}{*}{$\begin{array}{l}\text { Mean difference }(95 \% \mathrm{Cl}) \text {, } \\
\text { p value }\end{array}$} \\
\hline & $\begin{array}{l}\text { BPD } \\
n=89\end{array}$ & $\begin{array}{l}\text { No BPD } \\
n=151\end{array}$ & & $\begin{array}{l}\text { BPD } \\
n=77\end{array}$ & $\begin{array}{l}\text { No BPD } \\
n=132\end{array}$ & \\
\hline \multicolumn{7}{|l|}{$\mathrm{FEV}_{1}$} \\
\hline z-score & $-1.23(1.14)$ & $-0.76(0.98)$ & $-0.47(-0.75$ to -0.20$), 0.001$ & $-1.46(1.14)$ & $-0.77(0.96)^{*}$ & $-0.68(-0.98$ to -0.39$),<0.001$ \\
\hline$\%$ predicted & $85.3(13.9)$ & $90.9(11.7)$ & $-5.7(-9.2$ to -2.2$), 0.001$ & $82.7(13.7)$ & $90.9(11.4)^{*}$ & $-8.1(-11.6$ to 4.7$),<0.001$ \\
\hline \multicolumn{7}{|l|}{ FVC } \\
\hline z-score & $-1.16(1.31)$ & $-0.72(1.10)$ & $-0.39(-0.70$ to -0.08$), 0.014$ & $-0.68(1.14)$ & $-0.36(0.95)$ & $-0.32(-0.61$ to -0.029$), 0.030$ \\
\hline$\%$ predicted & $86.4(15.5)$ & $91.5(13.0)$ & $-5.1(-8.8$ to -1.5$), 0.006$ & $92.1(13.3)$ & $95.8(11.2)$ & $-3.6(-7.0$ to -0.2$), 0.036$ \\
\hline \multicolumn{7}{|l|}{$\mathrm{FEV}_{1} / \mathrm{FVC}$} \\
\hline z-score & $0.03(1.56)$ & $0.14(1.49)$ & $-0.11(-0.50$ to 0.29$), 0.60$ & $-1.17(1.35)$ & $-0.67(1.15)^{*}$ & $-0.51(-0.85$ to -0.16$), 0.004$ \\
\hline$\%$ & $87.9(9.4)$ & $88.7(9.0)$ & $-0.8(-3.2$ to 1.6$), 0.52$ & $78.6(10.6)$ & $83.3(8.4)^{*}$ & $-4.6(-7.3$ to -2.0$),<0.001$ \\
\hline \multicolumn{7}{|l|}{$\mathrm{FEF}_{25 \%-75 \%}$} \\
\hline z-score & $-1.56(1.09) \dagger$ & $-1.22(1.09) \ddagger$ & $-0.34(-0.63$ to -0.05$), 0.021$ & $-1.79(1.23)$ & $-1.12(1.10)$ & $-0.67(-0.99$ to -0.34$),<0.001$ \\
\hline$\%$ predicted & $67.0(22.6) \dagger$ & $74.0(23.4) \ddagger$ & $-7.0(-13.2$ to -0.8$), 0.026$ & $65.3(22.6)$ & $77.7(21.9)$ & $-12.4(-18.7$ to -6.2$),<0.001$ \\
\hline \multicolumn{7}{|l|}{$\mathrm{FEF}_{75 \%}$} \\
\hline z-score & $-0.83(1.15) \S$ & $-0.49(1.15) \uparrow$ & $-0.34(-0.66$ to -0.02$), 0.035$ & $-1.35(1.17)$ & $-0.71(1.06)^{*}$ & $-0.64(-0.95$ to -0.33$),<0.001$ \\
\hline$\%$ predicted & $79.1(33.0) \S$ & $89.1(37.0) 9$ & $-10.0(-19.8$ to -0.1$), 0.047$ & $66.4(28.6)$ & $82.3(30.6)^{*}$ & $-15.9(-24.4$ to -7.5$),<0.001$ \\
\hline \multicolumn{7}{|c|}{$\begin{array}{l}{ }^{*} n=1 \text { missing data. } \\
\text { tn}=2 \text { missing data. } \\
\ddagger n=5 \text { missing data. } \\
\S n=10 \text { missing data. } \\
\text { In=9 missing data. }\end{array}$} \\
\hline
\end{tabular}


Table 5 Changes over time for spirometric z-scores from linear mixed models within the preterm group, contrasting BPD and no BPD groups

\begin{tabular}{|c|c|c|c|}
\hline \multirow[b]{2}{*}{ Variable } & \multicolumn{2}{|l|}{ Change between 8 and 18 years } & \multirow[b]{2}{*}{ Interaction } \\
\hline & BPD & No BPD & \\
\hline $\mathrm{zFEV}_{1}$ & $-0.27(-0.47$ to -0.06$) p=0.012$ & $-0.04(-0.16$ to 0.09$) p=0.58$ & $-0.22(-0.44$ to -0.01$) p=0.044$ \\
\hline zFVC & $0.50(0.25$ to 0.75$) p<0.001$ & 0.33 (0.17 to 0.49$) p<0.001$ & $0.15(-0.12$ to 0.42$) p=0.28$ \\
\hline $\mathrm{zFEV}_{1} / \mathrm{FVC}$ & $-1.29(-1.66$ to -0.92$) p<0.001$ & $-0.74(-0.97$ to -0.51$) p<0.001$ & $-0.47(-0.86$ to -0.09$) \mathrm{p}=0.016$ \\
\hline $\mathrm{zFEF}_{25 \%-75 \%}$ & $-0.31(-0.53$ to -0.09$) p=0.006$ & $0.06(-0.10$ to 0.22$) p=0.44$ & $-0.36(-0.61$ to -0.10$) p=0.006$ \\
\hline $\mathrm{zFEF}_{75 \%}$ & $-0.56(-0.83$ to -0.29$) p<0.001$ & $-0.19(-0.38$ to -0.00$) p=0.049$ & $-0.34(-0.64$ to -0.03$) p=0.029$ \\
\hline
\end{tabular}

Values are mean difference $(95 \% \mathrm{Cl})$, unless otherwise stated.

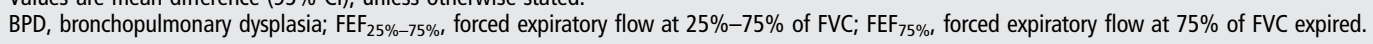

Table 6 Spirometry variables at 8 and 18 years within the preterm cohort, comparing smokers with non-smokers at 18 years

\begin{tabular}{|c|c|c|c|c|c|c|}
\hline \multirow[b]{2}{*}{ Variable } & \multicolumn{2}{|l|}{8 years } & \multirow[b]{2}{*}{$\begin{array}{l}\text { Mean difference }(95 \% \mathrm{Cl}) \text {, } \\
\text { p value }\end{array}$} & \multicolumn{2}{|l|}{18 years } & \multirow[b]{2}{*}{$\begin{array}{l}\text { Mean difference }(95 \% \mathrm{Cl}) \text {, } \\
\text { p value }\end{array}$} \\
\hline & $\begin{array}{l}\text { Smokers } \\
\mathrm{n}=34\end{array}$ & $\begin{array}{l}\text { Non-smokers } \\
n=163\end{array}$ & & $\begin{array}{l}\text { Smokers } \\
\mathrm{n}=35\end{array}$ & $\begin{array}{l}\text { Non-smokers } \\
n=170\end{array}$ & \\
\hline \multicolumn{7}{|l|}{$\mathrm{FEV}_{1}$} \\
\hline z-score & $-0.76(1.08)$ & $-0.96(1.05)$ & 0.20 (-0.20 to 0.59$), 0.33$ & $-1.17(0.98)$ & $-0.99(1.10)^{*}$ & $-0.18(-0.58$ to 0.22$), 0.37$ \\
\hline$\%$ predicted & $90.9(13.0)$ & $88.6(12.7)$ & $2.3(-2.4$ to 7.0$), 0.34$ & $86.2(11.6)$ & $88.2(13.1)^{*}$ & $-2.1(-6.8$ to 2.7$), 0.39$ \\
\hline \multicolumn{7}{|l|}{ FVC } \\
\hline z-score & $-0.62(1.01)$ & $-0.92(1.25)$ & $0.30(-0.15$ to 0.75$), 0.19$ & $-0.35(1.07)$ & $-0.49(1.03)$ & $0.15(-0.23$ to 0.52$), 0.45$ \\
\hline$\%$ predicted & $92.6(12.1)$ & $89.2(14.6)$ & $3.4(-1.8$ to 8.7$), 0.20$ & $96.0(12.5)$ & $94.2(12.0)$ & $1.7(-2.7$ to 6.2$), 0.45$ \\
\hline \multicolumn{7}{|l|}{$\mathrm{FEV}_{1} / \mathrm{FVC}$} \\
\hline z-score & $-0.07(1.62)$ & $0.14(1.51)$ & -0.21 ( -0.78 to 0.36$), 0.46$ & $-1.16(1.26)$ & $-0.79(1.25)^{*}$ & $-0.37(-0.83$ to 0.09$), 0.11$ \\
\hline$\%$ & $87.1(9.9)$ & $88.7(9.1)$ & $-1.6(-5.1$ to 1.8$), 0.35$ & $78.9(10.3)$ & $82.0(9.4)^{*}$ & $-3.1(-6.6$ to 0.4$), 0.08$ \\
\hline \multicolumn{7}{|l|}{$\mathrm{FEF}_{25 \%-75 \%}$} \\
\hline z-score & $-1.41(0.98)$ & $-1.31(1.17) \dagger$ & $-0.10(-0.53$ to -0.32$), 0.64$ & $-1.68(1.11)$ & $-1.30(1.21)$ & $-0.38(-0.81$ to 0.06$), 0.09$ \\
\hline$\%$ predicted & $69.9(20.2)$ & $72.2(25.0) \dagger$ & $-2.3(-11.4$ to 6.7$), 0.61$ & $67.0(20.1)$ & $74.4(23.4)$ & $-7.4(-15.8$ to 1.0$), 0.08$ \\
\hline \multicolumn{7}{|l|}{$\mathrm{FEF}_{75 \%}$} \\
\hline z-score & $-0.49(1.02) \ddagger$ & $-0.61(1.25) \S$ & $0.12(-0.36$ to 0.61$), 0.62$ & $-1.28(1.09)$ & $-0.88(1.15)^{*}$ & $-0.40(-0.82$ to 0.02$), 0.06$ \\
\hline$\%$ predicted & $88.0(29.2) \ddagger$ & $86.2(39.3) \S$ & $1.7(-13.4$ to 16.9$), 0.82$ & $67.4(27.0)$ & $78.3(31.5)^{*}$ & $-10.9(-22.2$ to 0.4$), 0.06$ \\
\hline
\end{tabular}

evidence that the smokers deteriorated between 8 and 18 years in $\mathrm{zFEV}_{1}$, and weaker evidence for $\mathrm{zFEF}_{75 \%}$.

\section{BDRs at 18 years}

The preterm group had a larger response in $\mathrm{FEV}_{1}$ to salbutamol, and more had a clinically significant BDR at 18 years than did controls (table 8). Within the preterm group, only those with BPD in the newborn period, but not those who were smokers at 18 years, had larger BDRs and higher odds of a clinically important BDR than participants without these characteristics (table 8).

\section{Gestational age at birth}

Within the preterm group alone, there was no effect of gestational age at birth on any of the analyses (data not shown).

\section{DISCUSSION}

EP or extremely low-birthweight survivors born in the surfactant era had greater airway obstruction compared with normal birth weight controls at both 8 and 18 years of age. Importantly, they had greater increases in airway obstruction between 8 and 18 years compared with controls, as hypothesised, which suggests they are highly unlikely to reach the peak of normal airway growth by their mid-20s that would be expected in the normal population. Within the preterm population, those who had BPD in the newborn period and those who were active smokers at 18 had greater increases in airway obstruction from 8 to 18 years, as hypothesised. Some of the airway obstruction may be reversible, as evidenced by the BDRs, particularly in those who had BPD in the newborn period, but not so in those who were smoking at 18 years.

The magnitudes of the deficits in spirometry variables at 18 years in the preterm group compared with controls in our study are similar to those of the other studies that have reported outcomes in late adolescence or early adulthood. The deficits are typically around 1 SD if expressed as z-scores, or 10\%-15\% predicted if expressed as per cent predicted for age, height and sex. The major differences between our study and others that have reported outcomes into late adolescence or early adulthood are that our study has participants with the lowest mean gestational ages and birth weights; all but one study predates the surfactant era; and serial spirometry data from earlier in childhood into adulthood have only been reported in three other studies. In none of those three studies were the reference 
Table 7 Changes over time for spirometric z-scores from linear mixed models within the preterm group, contrasting smoking and not smoking groups

\begin{tabular}{|c|c|c|c|}
\hline \multirow[b]{2}{*}{ Variable } & \multicolumn{2}{|l|}{ Change between 8 and 18 years } & \multirow[b]{2}{*}{ Interaction } \\
\hline & Smoking at 18 years & Not smoking at 18 years & \\
\hline $\mathrm{zFEV}_{1}$ & $-0.40(-0.70$ to -0.10$) p=0.011$ & $-0.06(-0.17$ to 0.06$) p=0.36$ & $-0.35(-0.63$ to -0.07$) \mathrm{p}=0.015$ \\
\hline zFVC & $0.30(0.00$ to 0.59$) p=0.05$ & $0.42(0.27$ to 0.57$) p<0.001$ & $-0.13(-0.48$ to 0.22$) p=0.47$ \\
\hline $\mathrm{zFEV}_{1} / \mathrm{FVC}$ & $-1.11(-1.59$ to -0.62$) p<0.001$ & $-0.92(-1.14$ to -0.71$) p<0.001$ & $-0.17(-0.68$ to 0.34$) p=0.51$ \\
\hline $\mathrm{zFEF}_{25 \%-75 \%}$ & $-0.28(-0.61$ to 0.05$) p=0.09$ & $-0.02(-0.17$ to 0.12$) p=0.74$ & $-0.25(-0.59$ to 0.08$) p=0.14$ \\
\hline $\mathrm{zFEF}_{75 \%}$ & $-0.61(-0.98$ to -0.24$) p=0.002$ & $-0.27(-0.44$ to -0.11$) p=0.001$ & $-0.41(-0.82$ to 0.00$) p=0.05$ \\
\hline
\end{tabular}

Values are mean difference $(95 \% \mathrm{Cl})$, unless otherwise stated.

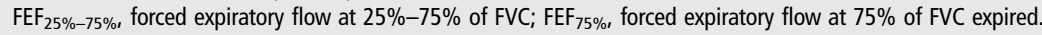

Table 8 Bronchodilator responses at 18 years in various groups-changes in FEV 1 post salbutamol

\begin{tabular}{|c|c|c|c|c|c|}
\hline \multicolumn{2}{|c|}{ Continuous mean (SD) } & \multirow[t]{2}{*}{ Mean difference $(95 \% \mathrm{Cl})$} & \multicolumn{2}{|c|}{$>12 \%$ increase $\%(n / N)$} & \multirow[t]{2}{*}{ OR $(95 \% \mathrm{Cl})$} \\
\hline Both groups & & & & & \\
\hline Preterm & Control & & Preterm & Control & \\
\hline $6.3(7.2) n=203$ & $3.7(5.5) n=151$ & 2.6 (1.3 to 4.0$) p<0.001$ & $12 \%[25 / 203]$ & $5 \%[7 / 151]$ & 2.89 (1.22 to 6.85$) \mathrm{p}=0.013$ \\
\hline \multicolumn{6}{|c|}{ Preterm group only } \\
\hline BPD & No BPD & & BPD & No BPD & \\
\hline $8.4(7.5) n=75$ & $5.1(6.8) n=128$ & $3.3(1.2$ to 5.3$) p=0.002$ & $21 \%[16 / 75]$ & $7 \%[9 / 128]$ & 3.58 (1.50 to 8.60$) p=0.003$ \\
\hline Smokers & Non-smokers & & Smokers & Non-smokers & \\
\hline $7.3(9.0) n=35$ & $6.2(6.8) n=164$ & $1.1(-1.5$ to 3.8$) p=0.41$ & $17 \%[6 / 35]$ & $12 \%[19 / 164]$ & $1.58(0.58$ to 4.30$) p=0.37$ \\
\hline
\end{tabular}

BPD, bronchopulmonary dysplasia.

equations used appropriate to span the relevant age groups, whereas we used the Global Lung Initiative equations designed to span ages 3-95 years; ${ }^{24}$ Quanjer et $a l^{25}$ have highlighted particular problems with older reference equations around 18 years of age, at the transition from childhood into adulthood, which is the reason that we could not report changes in lung volumes, such as residual volume and total lung capacity, over time. Narang et $a l^{16}$ from London reported on changes in spirometry between 7 and 9 years of age and 21 years of age in a cohort of birth weight $<2000 \mathrm{~g}$ born in $1979-1980$; $^{25}$ this is the only reported study where there were no substantial differences in spirometry variables between preterm and control groups in adulthood. In their 58 participants studied at 21 years, there were positive relationships between spirometry variables measured at the two time points. However, as they did not study the same controls at the earlier age, they could not determine if growth trajectories differed between preterm and control groups. Vollsaeter et $a l^{11}$ from Norway reported positive relationships between spirometry variables measured at 10 and 17 years of age in 35 participants born $<29$ weeks or $<1001 \mathrm{~g}$ in 1991-1992 and 35 controls. In contrast with our study, they did not find evidence of differential growth over time between preterm and control groups, perhaps because their study had a much smaller sample than ours or because the time interval between measurements was shorter ( 7 vs 10 years in our study). Their study was the only other reporting outcomes from children treated with surfactant, although infants were only treated within the context of a randomised controlled trial of early versus delayed surfactant, ${ }^{26}$ whereas in our study, treatment with surfactant was decided by the treating clinicians. Gibson et $a l^{14}$ reported respiratory outcomes to 25 years of age of a cohort of birth weight $<1501 \mathrm{~g}$ born in 1977-1982 (ie, the presurfactant era) from a single centre in Melbourne, Australia.
In that study, there were strong linear relationships between spirometric values from earlier in childhood (at 8, 11, 14 and 18 years) with those at 25 years; the relationships were stronger with diminishing time interval between comparisons, and were stronger in preterm survivors who had BPD than those who did not. However, they could not assess differential growth effects between preterm and control groups from 8 years of age in that study, as the control group was only studied at 14,18 and 25 years. The same group reported a significant decline in the $\mathrm{FEV}_{1} / \mathrm{FVC}$ ratio, expressed as an absolute percentage, between 8 and 18 years, in the preterm participants from the late $1970 \mathrm{~s}$ who had BPD compared with those without BPD. ${ }^{8}$ The current study is the only one to report increasing airway obstruction between 8 and 18 years in preterm children compared with controls.

This is the largest regional EP/ELBW cohort to report spirometry data to late adolescence in the postsurfactant era, with the added strength of a contemporaneous control group recruited at birth. Spirometry values were obtained blinded to study group. The results are applicable to EP/ELBW babies born today, until superseded by more contemporary data. A relative limitation of the study is the lower follow-up at 18 years, but few other studies of spirometry in late adolescence or early adulthood are derived from complete populations. Moreover, the linear mixed models allow data from all subjects with at least one value at either age to be included in the analyses. Another limitation is that we did not confirm smoking status with biochemical measurements, such as urinary cotinine. However, in a previous study of preterm survivors at a similar age where we did confirm smoking status with urinary cotinine values, we found that a history of smoking was very reliable, ${ }^{27}$ and we have no reason to believe that the current cohort would be any different. In that study, we found an adverse association between current 
smoking and airway obstruction at a mean age of 20 years in 44 subjects born $<1000 \mathrm{~g}$ in 1977-1980, before surfactant was available, ${ }^{27}$ consistent with the airway obstruction observed in the current study of EP/ELBW survivors at 18 years. Another limitation is that there were incomplete data for smoking and asthma at 18 years as not all participants completed the relevant questionnaires; this would have had little effect on the overall results as the numbers with missing data were small. We have deliberately not reported outcomes by surfactant treatment as only the infants with the most severe lung disease were treated with surfactant in our study; such a comparison should be limited to reports from randomised controlled trials of surfactant therapy. One small randomised trial reported improved airway flow in children aged 7-12 years who had been treated with surfactant compared with those treated with placebo in the newborn period. ${ }^{28}$ We have other respiratory data on the cohort at 18 years of age, such as transfer factor for carbon monoxide and exercise capacity, but not at 8 years of age, and hence we cannot describe changes over time in these variables, which was the aim of the current study.

Different rates of dysanapsis, or differential growth of the airways relative to the lung parenchyma, is a possible explanation for the differences in rate of change in the FVC between the two groups. Dysanapsis occurs in health during pubertal lung growth. We did not specifically determine the stage of puberty in this cohort at 18 years, but none were prepubertal; it is possible that variation in pubertal development may have contributed to differential rates of airway growth between the two cohorts.

In conclusion, EP/ELBW survivors from the surfactant era have greater impairments in airflow in childhood and late adolescence compared with controls. As BPD still occurs in one-third of EP/ELBW survivors despite the introduction of surfactant, and survivors who had BPD have even worse airway obstruction, other strategies must be investigated to reduce its incidence. Importantly, the airflow obstruction established in early childhood worsens through adolescence, which highlights the need for interventions to reduce the airway remodelling that accompanies long-standing airway obstruction. It is unlikely that EP/ELBW survivors, particularly those who had BPD or who are smokers, will reach normal airway capacity by their mid-20s, but the cohorts must be studied again at this age to determine their outcome. There is some hope for the smokers as cessation of smoking is known to diminish the rate of decline in $\mathrm{FEV}_{1}$ in adulthood; ${ }^{29}$ the challenge is to ensure that the smokers give up the habit, or, even better, not start in the first place.

\footnotetext{
Author affiliations

${ }^{1}$ Premature Infant Follow-up Programme, Royal Women's Hospital, Parkville, Victoria, Australia

${ }^{2}$ Department of Obstetrics and Gynaecology, University of Melbourne, Parkville, Victoria, Australia

${ }^{3}$ Clinical Sciences, Murdoch Childrens Research Institute, Parkville, Victoria, Australia ${ }^{4}$ Department of Paediatrics, University of Melbourne, Parkville, Victoria, Australia ${ }^{5}$ Thoracic Medicine, Royal Children's Hospital, Parkville, Victoria, Australia ${ }^{6}$ Clinical Epidemiology and Biostatistics, Murdoch Childrens Research Institute, Parkville, Victoria, Australia
}

Collaborators Members of the Victorian Infant Study Group: Peter Anderson, PhD: Clinical Sciences, Murdoch Childrens Research Institute, Parkville, Australia; Department of Paediatrics, University of Melbourne, Parkville, Australia. Alice Burnett, PhD: Clinical Sciences, Murdoch Childrens Research Institute, Parkville, Australia; Department of Paediatrics, University of Melbourne, Parkville, Australia; Premature Infant Follow-Up Program, the Royal Women's Hospital, Parkville, Australia. Catherine Callanan, RN: Premature Infant Follow-Up Program, the Royal Women's Hospital, Parkville, Australia. Elizabeth Carse, FRACP: Monash Newborn
Monash Medical Centre, Melbourne, Australia. Margaret P Charlton, MEd Psych: Monash Newborn, Monash Medical Centre, Melbourne, Australia. Jeanie Cheong, MD: Clinical Sciences, Murdoch Childrens Research Institute, Parkville, Australia; Premature Infant Follow-Up Program, the Royal Women's Hospital, Parkville, Australia; Department of Obstetrics and Gynaecology, University of Melbourne, Parkville, Australia. Noni Davis, FRACP: Premature Infant Follow-Up Program, the Royal Women's Hospital, Parkville, Australia. Lex W Doyle, MD: Clinical Sciences, Murdoch Childrens Research Institute, Parkville, Australia; Department of Paediatrics, University of Melbourne, Parkville, Australia; Premature Infant Follow-Up Program, the Royal Women's Hospital, Parkville, Australia; Department of Obstetrics and Gynaecology, University of Melbourne, Parkville, Australia. Julianne Duff, FRACP Premature Infant Follow-Up Program, the Royal Women's Hospital, Parkville, Australia. Esther Hutchinson, BSc (Hons): Premature Infant Follow-Up Program, the Royal Women's Hospital, Parkville, Australia. Marie Hayes, RN: Monash Newborn, Monash Medical Centre, Melbourne, Australia. Elaine Kelly, MA: Neonatal Services, Mercy Hospital for Women, Melbourne, Australia. Katherine J Lee, PhD: Clinical Epidemiology and Biostatistics, Murdoch Childrens Research Institute, Melbourne, Australia. Marion McDonald, RN: Premature Infant Follow-Up Program, the Royal Women's Hospital, Parkville, Australia. Gillian Opie, FRACP: Neonatal Services, Mercy Hospital for Women, Melbourne, Australia. Gehan Roberts, MPH, PhD, FRACP: Clinical Sciences, Murdoch Childrens Research Institute, Parkville, Australia. Andrew Watkins, FRACP: Neonatal Services, Mercy Hospital for Women, Melbourne, Australia. Amanda Williamson: Neonatal Services, Mercy Hospital for Women, Melbourne, Australia. Heather Woods, RN: Neonatal Services, Mercy Hospital for Women, Melbourne, Australia.

Contributors LWD: designed the study, supervised collection of all of the data, edited and checked the data, analysed and interpreted the data, wrote the first draft of the paper and approved the submitted version. A-MA: collected the respiratory data, interpreted the data, contributed to the writing of the paper and approved the submitted version. CR: designed the study, supervised the collection of the respiratory data, interpreted the data, contributed to the writing of the paper and approved the submitted version. SR: supervised the collection of the respiratory data, interpreted the data, contributed to the writing of the paper and approved the submitted version. NMD: contributed to the design of the study, collected some of the data, interpreted the data, contributed to the writing of the paper and approved the submitted version. KJL: helped with the analysis and interpretation of the data, contributed to the writing of the paper and approved the submitted version. JLC: designed the study, interpreted the data, contributed to the writing of the paper and approved the submitted version.

Funding National Health and Medical Research Council of Australia: Project Grant \#491246; Program Grant \#606789; Centre of Clinical Research Excellence Grant \#546519; Centre of Research Excellence Grant \#1060733; Early Career Fellowship Grant \#1053787. Victorian Government's Operational Infrastructure Support Program.

Competing interests None declared.

Patient consent Obtained.

Ethics approval HREC at Royal Women's Hospital, Melbourne.

Provenance and peer review Not commissioned; externally peer reviewed.

\section{REFERENCES}

1 Stocks J, Hislop A, Sonnappa S. Early lung development: lifelong effect on respiratory health and disease. Lancet Respir Med 2013;1:728-42.

2 James $A L$, Palmer $\mathrm{L}$, Kicic $\mathrm{E}$, et al. Decline in lung function in the Busselton Health Study: the effects of asthma and cigarette smoking. Am J Respir Crit Care Med 2005; 171:109-14.

3 Northway WH Jr, Rosan RC, Porter DY. Pulmonary disease following respirator therapy of hyaline-membrane disease. Bronchopulmonary dysplasia. N Engl J Med 1967;276:357-68.

4 Jobe $\mathrm{AH}$, Bancalari E. Bronchopulmonary dysplasia. Am J Respir Crit Care Med 2001;163:1723-9.

5 Doyle LW, Roberts G, Anderson PJ. Changing long-term outcomes for infants 500 $999 \mathrm{~g}$ birth weight in Victoria, 1979-2005. Arch Dis Child Fetal Neonatal Ed 2011;96:F443-F47.

6 Doyle LW, Roberts G, Anderson PJ. Outcomes at age 2 years of infants $<28$ weeks gestational age born in Victoria in 2005. J Pediatr 2010;156:49-53.e1.

7 Northway WH Jr, Moss RB, Carlisle KB, et al. Late pulmonary sequelae of bronchopulmonary dysplasia. N Engl J Med 1990;323:1793-9.

8 Doyle LW, Faber B, Callanan C, et al. Bronchopulmonary dysplasia in very low birth weight subjects and lung function in late adolescence. Pediatrics 2006:118:108-13.

9 Vrijlandt EJ, Gerritsen J, Boezen HM, et al. Lung function and exercise capacity in young adults born prematurely. Am J Respir Crit Care Med 2006;173:890-6. 
10 Evensen KA, Steinshamn S, Tjønna AE, et al. Effects of preterm birth and fetal growth retardation on cardiovascular risk factors in young adulthood. Early Hum Dev 2009;85:239-45.

11 Vollsaeter $M$, Røksund $O D$, Eide $G E$, et al. Lung function after preterm birth: development from mid-childhood to adulthood. Thorax 2013;68:767-76.

12 Vollsaeter M, Clemm HH, Satrell E, et al. Adult respiratory outcomes of extreme preterm birth. A regional cohort study. Ann Am Thorac Soc 2015;12:313-22.

13 Gough A, Linden M, Spence D, et al. Impaired lung function and health status in adult survivors of bronchopulmonary dysplasia. Eur Respir J 2014;43:808-16.

14 Gibson AM, Reddington C, McBride L, et al. Lung function in adult survivors of very low birth weight, with and without bronchopulmonary dysplasia. Pediatr Pulmonol 2015:50:987-94

15 Saarenpää HK, Tikanmäki M, Sipola-Leppänen $M$, et al. Lung Function in Very Low Birth Weight Adults. Pediatrics 2015;136:642-50.

16 Narang I, Rosenthal M, Cremonesini D, et al. Longitudinal evaluation of airway function 21 years after preterm birth. Am J Respir Crit Care Med 2008;178:74-80.

17 Gold DR, Wang X, Wypij D, et al. Effects of cigarette smoking on lung function in adolescent boys and girls. N Engl J Med 1996;335:931-7.

18 Doyle LW, Bowman E, Callanan C, et al. Improved outcome into the 1990s for infants weighing 500-999 g at birth. Arch Dis Child Fetal Neonatal Ed 1997;77:F91-4.

19 Doyle LW, Bowman E, Callanan C, et al. Outcome at 2 years of children 23-27 weeks' gestation born in Victoria in 1991-92. The Victorian Infant Collaborative Study Group. J Paediatr Child Health 1997;33:161-5.

20 Doyle LW, the Victorian Infant Collaborative Study Group. Outcome at 5 years of age of children 23 to 27 weeks' gestation: refining the prognosis. Pediatrics 2001;108:134-41.
21 Doyle LW, Anderson PJ. Improved neurosensory outcome at 8 years of age of extremely low birthweight children born in Victoria over three distinct eras. Arch Dis Child Fetal Neonatal Ed 2005;90:F484-8.

22 Doyle LW, the Victorian Infant Collaborative Study Group. Respiratory function at age 8-9 years in extremely low birthweight/very preterm children born in Victoria in 1991-92. Pediatr Pulmonol 2006;41:570-6.

23 Miller MR, Hankinson J, Brusasco V, et al. Standardisation of spirometry. Eur Respir J 2005;26:319-38.

24 Quanjer PH, Stanojevic S, Cole TJ, et al. Multi-ethnic reference values for spirometry for the 3-95-yr age range: the global lung function 2012 equations. Eur Respir J 2012;40:1324-43.

25 Quanjer $\mathrm{PH}$, Hall GL, Stanojevic $\mathrm{S}$, et al. Age- and height-based prediction bias in spirometry reference equations. Eur Respir J 2012;40:190-7.

26 Early versus delayed neonatal administration of a synthetic surfactant-the judgment of OSIRIS. The OSIRIS Collaborative Group (open study of infants at high risk of or with respiratory insufficiency - the role of surfactant. Lancet 1992;340:1363-9.

27 Doyle LW, Olinsky A, Faber B, et al. Adverse effects of smoking on respiratory function in young adults born weighing less than 1000 grams. Pediatrics 2003;112Pt 1):565-9.

28 Pelkonen AS, Hakulinen AL, Turpeinen $M$, et al. Effect of neonatal surfactant therapy on lung function at school age in children born very preterm. Pediatr Pulmonol 1998;25:182-90.

29 Anthonisen NR, Connett JE, Murray RP. Smoking and lung function of Lung Health Study participants after 11 years. Am J Respir Crit Care Med 2002;166:675-9. 